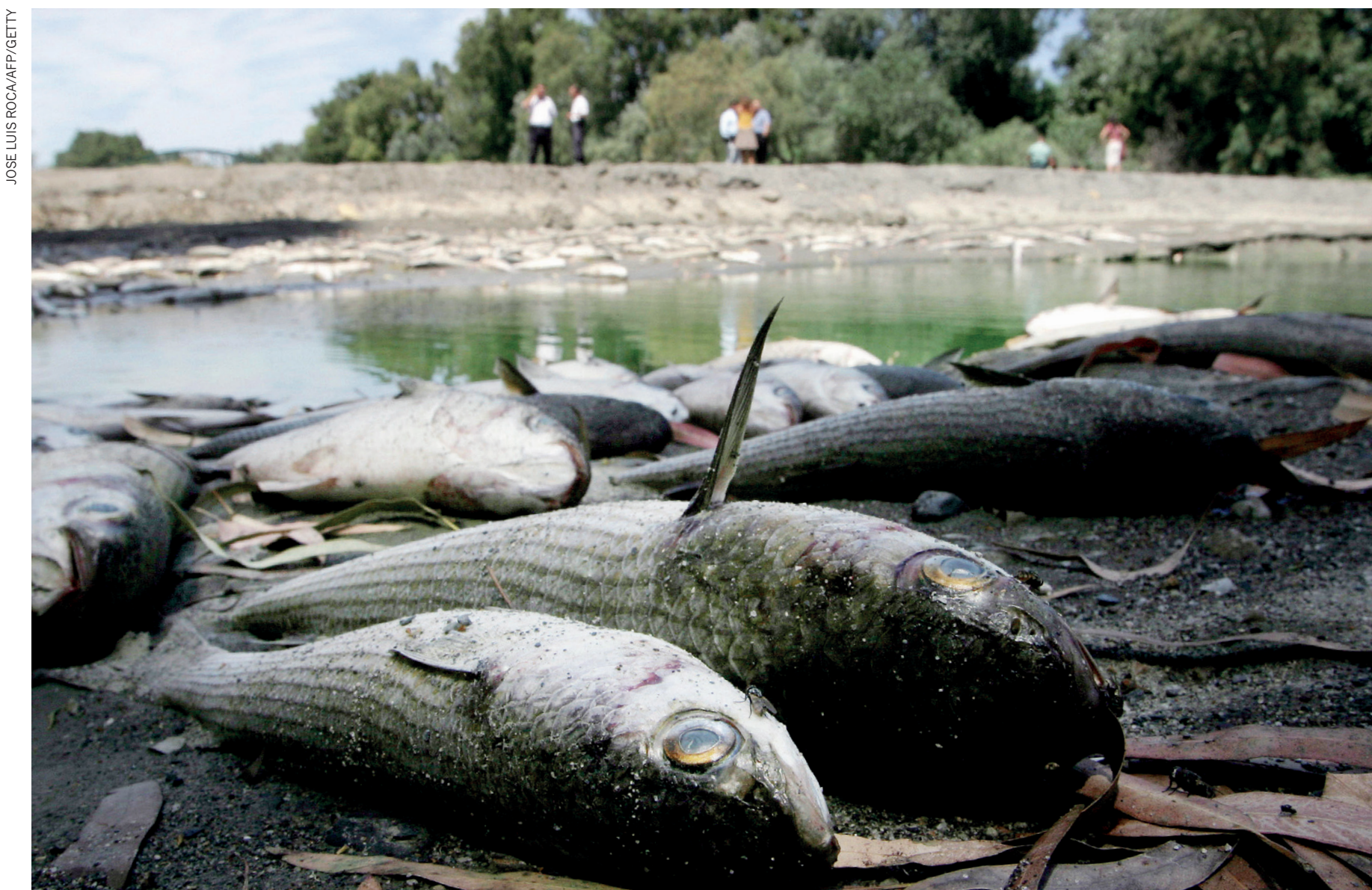

Dead fish on the banks of the Guadiaro River in southern Spain during severe drought.

\title{
Prepare river ecosystems for an uncertain future
}

\section{As the climate warms, we can't restore waterways to pristine condition, but models} can predict potential changes, argue Jonathan D. Tonkin, N. LeRoy Poff and colleagues.

$\mathrm{I}$ January, millions of fish died in Australia's Murray-Darling Basin as the 1 region experienced some of its driest and hottest weather on record. The heat also caused severe water shortages for people living there. Such harsh conditions will become more common as the world warms. Iconic and valuable species such as the Murray cod (Maccullochella peelii peelii) - Australia's largest freshwater fish - could vanish, threatening biodiversity and livelihoods.

Rivers around the world are struggling to cope with changing weather patterns. In Germany and Switzerland, a heatwave last year killed thousands of fish and blocked shipping on the River Rhine. California is emerging from a six-year drought ${ }^{1}$ that restricted water supplies and devastated trees, fish and other aquatic life. Across the US southwest, extended dry spells are destroying many more forests and wetlands.

What should river managers do? They cannot look to tools of old: conventional management techniques that aim to restore ecosystems to their original state. Ongoing human development and climate change mean that this is no longer possible. And models based on past correlations do a poor job of predicting how species might respond to unprecedented changes in future (see 'Ecosystem change'). A different approach is called for.

To maintain water supplies and avoid devastating population crashes, rivers must be managed adaptively, enhancing their resilience and limiting risk. Researchers must also develop better forecasting tools that can project how key species, life stages and ecosystems might respond to environmental changes. This will mean moving beyond simply monitoring the state of ecosystems to modelling the biological mechanisms that underpin their survival.

\section{MODEL PROCESS}

Today, river managers track properties such as species diversity and population abundance, and compare them with historical averages. If they spot troubling declines, they might intervene by, for instance, altering the amount of water released from dams. But by the time trends are detected, they can be impossible to arrest.

Understanding how sensitive ecosystems might change is crucial to managing them in the future. For example, in the American west, native cottonwoods (Populus spp.) are 
valuable, long-lived trees that anchor river banks and offer habitats for many species. They are finely tuned to seasonal flood patterns, releasing their seeds in early summer when river flows peak. The seeds take root in moist ground after the flood recedes ${ }^{2}$. But if the flood is delayed, even by a few days, many seeds fall on dry ground and die. Droughttolerant species, such as salt cedar (Tamarix ramosissima), that disperse seeds over a longer period will move in and dramatically alter conditions for native flora and fauna.

Models based on biological processes or mechanisms - that is, how rates of survival, reproduction and dispersal vary with environmental conditions - can follow and predict such shifts. For example, by modelling the impacts of changes in flood timing on aquatic invertebrates, it is possible to predict how the numbers of dragonflies and mayflies in a dryland river will vary with different patterns of dam releases ${ }^{3}$.

Process-based models can be tailored to particular life stages of a species, or sequences of events ${ }^{4}$. They can identify tipping points and bottlenecks. For example, they have revealed that the early juvenile stage of coho salmon (Oncorhynchus kisutch) in the northwestern United States is most sensitive to summer droughts. The salmon spawn in streams that flow into coastal rivers, and might spend a couple of years in fresh water before moving to the sea. Juveniles might not survive, or might find it hard to travel downstream, when the river levels are low ${ }^{5}$.

Such models can also track how interactions among species in communities vary under changing conditions ${ }^{6}$. For example, the loss of riparian specialists in dryland river ecosystems and invasion by both nonnative and upland species in a drier future could create a vicious cycle ${ }^{6}$. River ecosystems could become more vulnerable to climate change and to alien species.

Armed with all this information, managers can intervene before a problem arises. For example, in wet years, conservationists in the Pacific Northwest could find and support habitats that are crucial to juvenile salmon.

\section{"Dam managers should focus on the most vulnerable or responsive life stages."}

They could manage water flows in dry years to enable the salmon to migrate. Similarly, in the US southwest, river flows could be increased strategically from reservoirs to protect important species, such as cottonwoods. And in Australia, letting more water pass through dams in spring could stop rivers drying up while the eggs of Murray cod mature ${ }^{7}$.

Rivers must also be managed for people. Allocating scarce water resources is contentious. Policymakers, water-resource engineers, conservationists and ecologists must work together to decide how much water should be diverted to people, agriculture and industry, and how much is needed to protect ecosystems during drought.
Some river basins are beginning to be managed adaptively — agencies are trying different management practices, learning from them and updating them as needed. For example, in Australia, state and federal agencies periodically reassess and rebalance water allocations, as climate trends, information and assessment tools develop. Similarly, the Bay-Delta Plan in California proposes to revisit relationships between target species, water flows and water quality in San Francisco Bay and the Sacramento-San Joaquin River Delta every five years.

But adaptive management alone might miss conservation targets. Unexpected consequences could emerge over the long term as impacts mount. Process-based models can look further ahead and save time, money and disruption by limiting the number of interventions as well as avoiding adverse impacts. They would help stakeholders and managers to choose which features of ecosystems to maintain, to justify costly interventions such as major engineering works and to weigh trade-offs to build resilience under increasing climatic uncertainty ${ }^{8}$.

\section{OBSTACLES TO IMPLEMENTATION}

Process-based models are already used in fisheries and conservation. For example, they have shown conservationists that it is more effective to protect juvenile loggerhead sea turtles from being caught in fishing nets than to safeguard their eggs on beaches ${ }^{9}$. And such models help to guide the management of wetland habitats in the

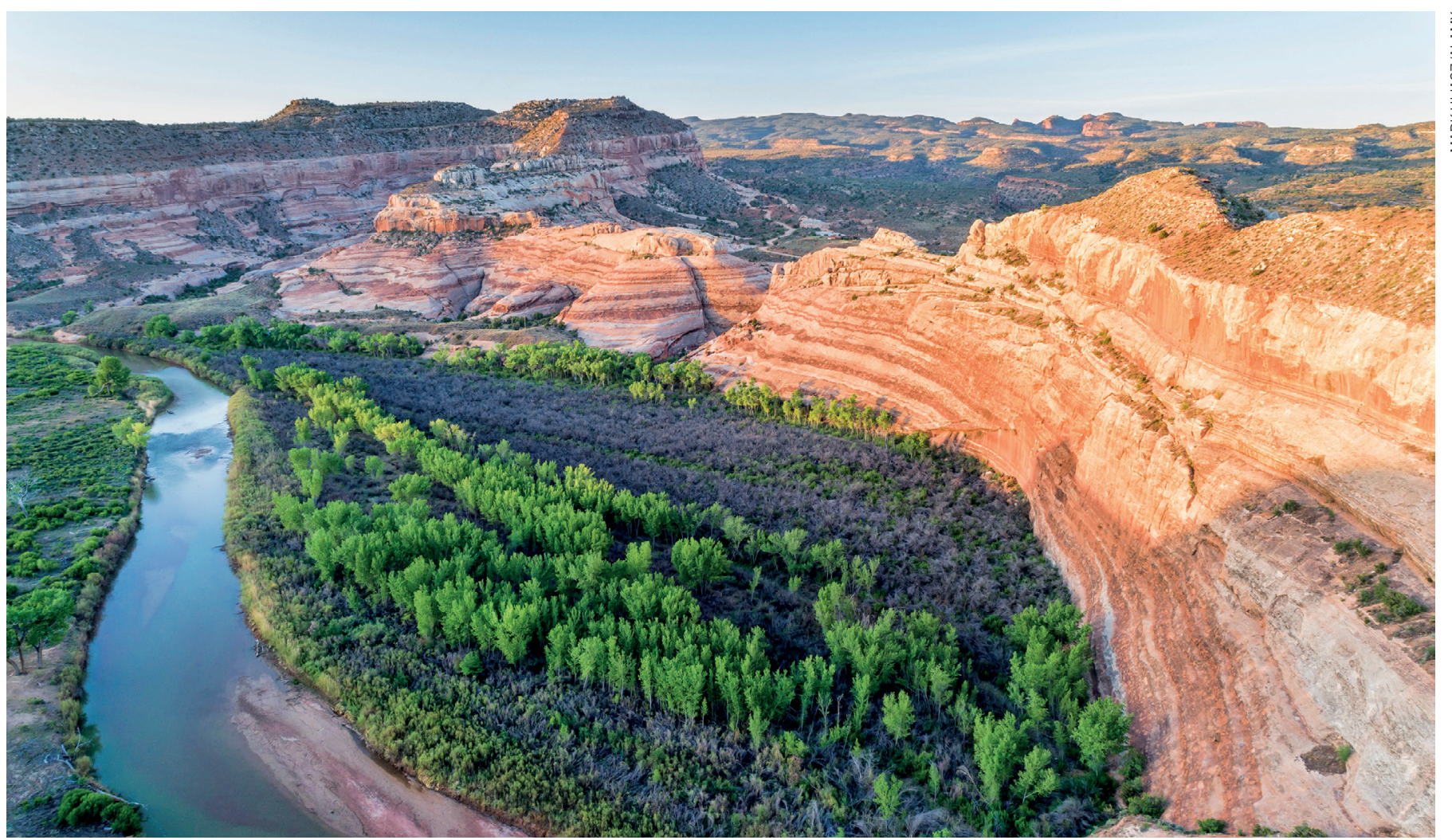

Native cottonwoods are being displaced by non-native salt cedar in the Dolores River, Utah, owing to flow alteration by damming. 


\section{ECOSYSTEM CHANGE}

Models of river ecosystems must describe how various species react as droughts become more common in a warmer climate over the next 200 years. Models that consider basic biology predict broader changes that linear extrapolations miss.

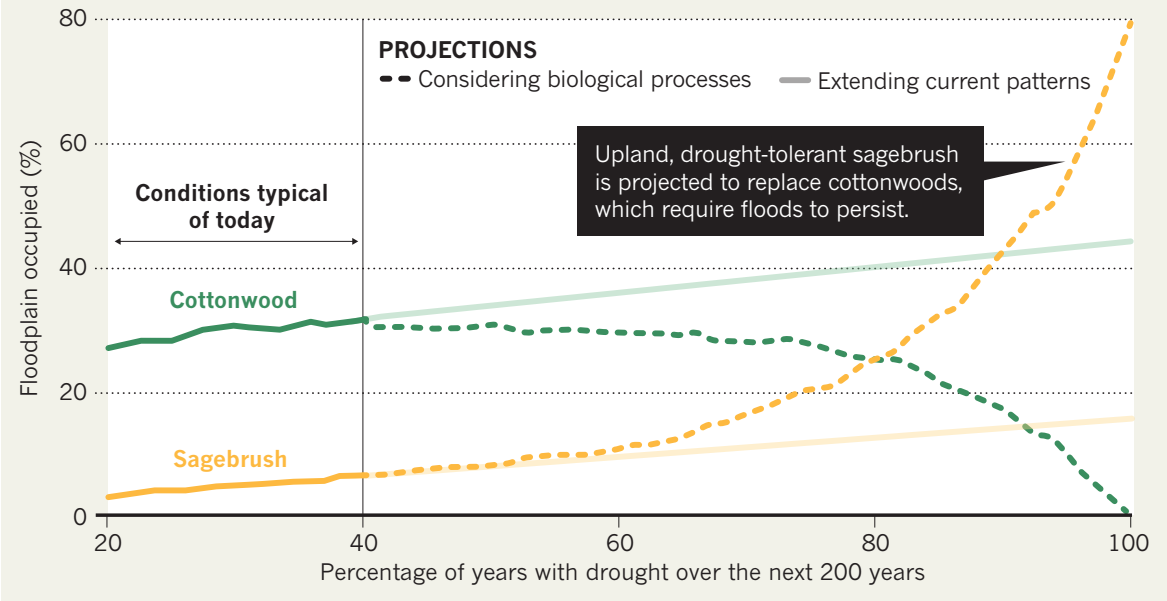

United States for the endangered Everglades snail kite (Rostrhamus sociabilis), the fledglings of which are susceptible to droughts ${ }^{10}$.

But they are rarely used in river management, mainly because data on the basic biology of local species are lacking. Such data are costly for scientists and agencies to collect. Measuring fecundity or survival, for example, takes years and thus requires longterm funding and commitment. Such campaigns are usually reserved for endangered or commercially valuable species.

Simplifying models might help to bridge the data gaps in the interim. Species with similar life histories or characteristics might respond similarly to changing river conditions. Studies of one could inform models and management of similar species in other places. For instance, plains cottonwood (Populus deltoides) in North America, river red gum (Eucalyptus camaldulensis) in Australia, and Euphrates poplar (Populus euphratica) in North Africa and Eurasia are all riparian trees that have similar hydrological requirements and drought tolerances. They share characteristics such as shallow roots and furrowed bark that resists flood scour, and can resprout after being buried by sediment. Analytical methods could also be developed to extrapolate across gaps in data sets.

\section{FOUR STEPS}

River scientists and managers should take the following steps.

Collect data on mechanisms. We call for a fresh global campaign to gather naturalhistory data on the responses of biodiversity to changes in river flow. Estimates of fecundity and survival at various life stages will require monitoring in the field. Other information, such as flood-induced mortality rates, could be gathered through field and laboratory experiments. Data from different sources can also be combined, including species traits, population abundances across life stages and remote-sensing data about the states of ecosystems on wider scales ${ }^{4}$.

We urge local, state and federal agencies, as well as researchers, non-governmental organizations and other bodies, to make existing data available. Facilities for hosting these already exist, such as the COMPADRE and COMADRE global databases, which hold population models for hundreds of plant and animal species, respectively. Organizations such as the Alliance for Freshwater Life, the wildlife charity WWF and the Group on Earth Observations Biodiversity Observation Network should lobby global funding bodies to support data collection.

Describe key processes in models. Scientists need to better articulate the relationships between population dynamics and waterflow patterns in process-based models. For example, the models need to describe how well different life stages of plants reproduce or survive under flood or drought conditions, the flow conditions and timing that are required for fish to reproduce or the growth rates of insect populations after floods of different sizes ${ }^{3-5,7}$. Outputs need to be expressed clearly so that river managers and decision makers can understand and use them.

Focus management on bottlenecks. Targeted interventions to avoid populations collapsing during extreme flows will be a cornerstone of managing rivers for resilience in future. Accordingly, dam managers should focus on the most vulnerable or responsive life stages, not just population abundance. Sadly, as flow extremes become more common, scientists and managers will be able to observe die-offs and calibrate the models.
Pinpoint uncertainty. The level of confidence that managers have in the results of models will influence how willing they will be to deal with varying levels of risk. Predictions should thus quantify the level of trust that can be placed in them. Scientists must present uncertainties in forecasts clearly. Models should be tested by hindcasting (predicting past or present population size, for example), and uncertainty in model inputs should be traced through to the outputs. The knowledge gaps that most compromise accuracy should be identified. The models should be regularly updated, tested and improved as new data arrive.

Freshwater biodiversity is disappearing on our watch. As the crisis deepens, we must model and manage rivers to safeguard the services they provide.

Jonathan D. Tonkin is a Rutherford Discovery Fellow in the School of Biological Sciences at the University of Canterbury, Christchurch, New Zealand. N. LeRoy Poff is a professor in the Department of Biology at Colorado State University, Fort Collins, USA, and at the Institute for Applied Ecology, University of Canberra, Australia. Nick R. Bond, Avril Horne, David M. Merritt, Lindsay V. Reynolds, Julian D. Olden, Albert Ruhi, David A. Lytle. e-mails: jonathan.tonkin@canterbury. ac.nz;n.poff@colostate.edu

1. Diffenbaugh, N. S., Swain, D. L. \& Touma, D. Proc. Natl Acad. Sci. USA 112, 3931-3936 (2015).

2. Mahoney, J. M. \& Rood, S. B. Wetlands 18 , 634-645 (1998).

3. McMullen, L. E., De Leenheer, P. Tonkin, J. D. \& Lytle D. A. Ecol. Lett. 20, 1566-1575 (2017).

4. Lytle, D. A., Merritt, D. M., Tonkin, J. D., Olden, J. D. \& Reynolds, L. V. Ecol. Appl. 27, 1338-1350 (2017).

5. Ohlberger, J. et al. Freshwater Biol. 63, 331-340 (2018).

6. Tonkin, J. D., Merritt, D. M., Olden, J. D., Reynolds, L. V. \& Lytle, D. A. Nature Ecol. Evol. 2, 86-93 (2018).

7. Yen, J. D. L., Bond, N. R., Shenton, W., Spring, D. A. \& Mac Nally, R. J. Appl. Ecol. $\mathbf{5 0}$ 691-701 (2013)

8. Poff, N. L. et al. Nature Clim. Change 6, 25-34 (2016)

9. Crouse, D. T., Crowder, L. B. \& Caswell, H. Ecology 68, 1412-1423 (1987).

10.Beissinger, S. R. Ecol. Appl. 5, 618-631 (1995).

\section{CORRECTIONS}

The Comment 'Make scientific data FAIR' (Nature 570, 27-29; 2019) wrongly stated that Springer Nature has signed up to the Enabling FAIR Data Project's Commitment Statement; so far, only Nature and Scientific Data have done so. The Comment 'Credit data generators for data reuse' (Nature 570, 30-32; 2019) wrongly located Julie Dunning Hotopp at the University of Maryland in College Park; in fact, she is in Baltimore. 